\title{
A Paler Shade of Green: Environmental Policy UNDER INDUCED TECHNICAL CHANGE*
}

\author{
Corrado Di Maria ${ }^{\dagger}$ \\ University of East Anglia
}

\author{
Sjak Smulders ${ }^{\ddagger}$ \\ Tilburg University
}

December 14, 2016

\begin{abstract}
Conventional wisdom argues that environmental policy is less costly if it induces the development of cleaner technologies. In contrast to this argument, we show that once the second-best nature of actual economies is taken into account, the cost of environmental policy may well be larger with induced technical change (ITC) than without. Thus, ITC may lower both the emissions reductions and the welfare gains associated with environmental policy. In an endogenous policy framework, ITC may reduce the desired stringency of the policy.
\end{abstract}

\section{JEL Classification: $\mathrm{H} 23, \mathrm{O} 38, \mathrm{Q} 55, \mathrm{Q} 58$}

Keywords: Environmental Policy, Innovation Policy, Induced Technical Change, Pollutionsaving Technical Change, Pollution-using Technical Change, Crowding-out, Second-best Policy.

*We would like to thank Michael Caputo, Carlo Carraro, Ujjayant Chakravorty, Julien Daubanes, Carolyn Fischer, Don Fullerton, Reyer Gerlagh, Larry Goulder, Glenn Harrison, Emma Hutchinson, Emiliya Lazarova, Ngo Van Long, Grischa Perino, Scott Taylor, and Aart de Zeeuw, as well as seminar participants at the London School of Economics, University of British Columbia, University of Central Florida, Université du Québec à Montréal, University of Birmingham, University of Stirling, CESifo, and the Potsdam Institute for Climate Change for comments on previous versions of this paper. This research did not receive any specific grant from funding agencies in the public, commercial, or not-for-profit sectors.

$\dagger$ Author for correspondence: School of Economics, University of East Anglia, Norwich Research Park, Norwich, NR4 7TJ, United Kingdom. E-mail:c.di-maria@uea.ac.uk.

†ilburg Sustainability Center, Department of Economics and CentER, Tilburg University, P.O. Box 90153, 5000 LE Tilburg, The Netherlands, E-mail:j . a.smulders@uvt.nl. Smulders is also a CESifo Research Network Fellow. 


\section{Introduction}

A widely held tenet among environmental economists and policy makers alike is that the development of new, cleaner technologies decreases the cost of pollution reductions. The natural consequence of this view is that policy-induced technical change lowers the costs of complying with environmental regulations and facilitates the implementation of ambitious environmental policies. This deep-rooted trust in the salvific power of technology, however, may appear unjustified in light of the historical record showing that over the course of the last two centuries a number of major technological developments ushered dramatic improvements in energy efficiency, while at the same time fostering large increases in energy use and polluting emissions. ${ }^{1}$ In other words, the process of technological change has in the past often proven to be pollution-using, rather than pollution-saving.

To explain this apparent paradox, it is useful to distinguish between the general notion that the adoption of new technologies responds to profit incentives, and the more specific notion whereby technological change responds to policies in so far as they affect profits - a distinction between endogenous innovation and policy-induced technical change. Within an endogenous innovation framework, firms implement innovations they expect to increase their profits, and the pollution-saving or pollution-using nature of the technology is immaterial. When environmental policy makes pollution more expensive, however, it also makes pollution-saving innovations relatively more profitable than pollution-using ones. For this reason in the dominant view (environmental) policy-induced technical change (ITC) is good for the environment: the policy aligns the innovative firm's profit motives with the policymaker's environmental goals and ITC makes the policy more effective and less costly.

In this paper we show that this view may break down in the presence of externalities, distortions, or general equilibrium effects. We emphasize two main avenues behind this result. On the one hand, while environmental policy would become cheaper if firms adopted pollution-saving technology, they may actually find it optimal to respond to changes in policy by instead adopting pollution-using technology if the latter turns out to be more profitable from their point of view. This may happen in a second-best world in which price distortions introduce a wedge between the firms' profit incentives and society's policy aims. On the other hand, even if firms focus on pollution-saving innovations, their response may impose a large enough cost to society to end up crowding out valuable innovations. ${ }^{2}$ The literature has so far widely neglected these possibilities, either by assuming that innovation can only be pollution-saving or by abstracting from second-best and general equilibrium issues.

The key mechanism by which ITC may increase the cost of environmental policy is thus by decoupling the private returns to investment in clean technologies from their social returns. To illustrate this mechanism, it is enough to consider the role of a simple production externality from pollution. As pollution falls, firms' production and profits benefit, but the firms themselves do not recognize this external effect when making decisions on their emis-

\footnotetext{
${ }^{1}$ Examples of such technologies are steam powered pumps and looms in the nineteenth century, internal combustion engines at the turn of the twentieth century, petrochemical plastics and fertilizers after World War II, jet planes for intercontinental flights in the 1960's, and personal computer and other information and communication technologies from the 1980's.

${ }^{2}$ This mechanism is similar to the scale effect emphasized in Gans (2012).
} 
sion levels and technologies. In the presence of such an externality, firms might profitably respond to the bigger market size by increasing their production and emissions, and by investing in polluting-using capital. To make matters worse, investment incentives may also be distorted by suboptimal policies, such as subsidies to polluting inputs that trigger pollution-using investment and innovation.

Our results challenge the conventional wisdom and show that ITC may raise the opportunity cost of pollution abatement, reduce the willingness to pay for environmental quality, or both. The presence of ITC may thus make environmental policy targets more costly to achieve, or lead to situations where policies become optimally less ambitious, implying lower pollution reductions. ${ }^{3}$ These results are at odds with most of the existing literature, which instead finds that ignoring ITC leads to overestimating the costs of environmental policy. ${ }^{4,5}$

In this paper, we use a stylized, static framework that lets us transparently identify the driving forces behind our results. These results are driven by a combination of elements that are empirically relevant but often neglected in other analyses of induced technical change. In particular, our conclusions emerge in a second-best world in which environmental quality affects productivity and thus interacts with investment decisions. We also find that they are more likely to arise when innovations lead to a significant increase in the demand for physical capital. Such complementarity between new technology and physical capital matches historical patterns of innovation and investment, with expansions in sectors where new products and improved technologies are introduced, and with displacements of older technologies by newer, more capital-intensive ones. ${ }^{6}$

In what follows, we show how two simple modifications of the standard set-up, introduced

\footnotetext{
${ }^{3}$ Note that, in the model presented below, environmental policy is both desirable, in the sense that it leads to welfare improvements, and effective, in the sense that it achieves pollution reductions. Our claim that ITC reduces the effectiveness or increases the cost of environmental policy refers to the comparison between an hypothetical world where technology is exogenously given, and the more realistic world in which technology and investment react to changes in the relative prices of production factors.

${ }^{4}$ In the context of climate change, the latest IPCC report discusses climate policy models with ITC and concludes that "These models demonstrate that ignoring induced innovation overstates the costs of climate control" (IPCC, 2014 p.257). Similar positions have been expressed in the well-known Stern Review (Stern 2006) and by Goulder (2004). Modelling efforts that support this view are discussed at length in the context of the Innovation Modelling Comparison Project by Edenhofer et al. (2006). An extreme representation of this paradigm is offered by Acemoglu et al. (2012), who show that environmental policy only needs to be temporary to prevent environmental collapse by redirecting technological change.

${ }^{5}$ As discussed later in the paper, a number of authors have previously argued that technical change might lead to an increases in the marginal cost of pollution abatement (Amir et al. 2008, Baker et al. 2008, Bauman et al. 2008 Perino and Requate, 2012, Brechet and Meunier 2014). We differ from these contribution in that their focus is on partial equilibrium models of technology adoption, whereas we provide a general equilibrium view of induced innovation in the presence of additional distortions. Gans (2012) finds that environmental policy may reduce innovation through a scale effect. Our results in the present paper generalize his findings since, rather than relying on specific functional forms, we derive our results in a general setting.

${ }^{6}$ Looking back to the list of innovations in footnote 1 one might think of the development of petrochemistry and plastics - whose versatility in production lead to a myriad novel uses - as well as jet engines used for transatlantic flights as examples of new products introduced with increased demand for capital as a result. The other technologies in that list fit better among the capital-intensive innovations. Large steam-powered iron pumps and mills replaced hand-operated wooden ones during the industrial revolution, automobiles replaced horses and carriages, etc.
} 
to capture empirically relevant features of environmental policy, have profound implications for policy outcomes. First, while we assume that the direct (ceteris-paribus) effect of new technology is to reduce pollution, our modelling reveals that the use of such technology may impact the environment adversely through indirect effects. In the first part of our paper we show that the general-equilibrium effect of the new technology can actually be either in favor or against the environment, depending on the degree to which new technology fosters demand for physical capital. Moreover, we demonstrate that firms faced with more stringent environmental regulation might decide to either increase or decrease their investment in new technology. Thus, more stringent environmental regulation does not necessarily lead to more technology creation, and might, instead, crowd-out such investment. We find, for example, that for both price and quantity instruments a tightening of the environmental regulation might either crowd-in brown technology or crowd it out, implying in each case very different effects on the marginal cost of pollution abatement. By contrast, most existing contributions studying the interaction between environmental policy and induced innovation assume implicitly or explicitly that investment in new technologies necessarily lowers the marginal cost of reducing emissions. Given such assumption, it is not surprising that environmental policy that increases investment lowers abatement costs, inducing additional emissions reductions (Goulder and Mathai, 2000; Nordhaus, 2002, Parry et al. 2003; Popp, 2004, Sue Wing, 2006, Gerlagh, 2007).

The second aspect in which our modelling choices differ from most other contributions in the literature is our explicit recognition that environmental policy is not conducted in a void, but it rather happens in the presence of a number of other externalities, notably externalities due to market failures in innovation (Jaffe et al., 2003). Realistically, our model captures the idea that existing policies may fail to correctly internalize the full social benefits from innovation (Griliches, 1992), at the same time that they provide excessive support to investments that complement polluting inputs such as coal or oil (Davis, 2014; Coady et al. 2015). This deviation from the first-best has important implications for the welfare consequences of environmental policy. In a context where (exogenous) environmental policy is arbitrarily tightened from an initial suboptimal level, for example, we show that it is possible for welfare to improve less under ITC than under exogenous technology. In an endogenous policy context, where the stringency of regulation depends on preferences, instead, the presence of additional distortions introduces the possibility that following an increase in the degree of 'greenness' of preferences, ITC may induce the regulator to become less ambitious in setting environmental targets. This is because in this context the desired reductions in pollution come at the cost of relatively larger falls in consumption, and/or because the regulator might optimally decide to trade-off smaller welfare gains in terms of pollution reductions against potential large welfare costs along other dimensions.

The main aim of this paper is to present a tractable model that generalizes existing approaches and allows us to derive novel results. Contrary to the dominant view, we show that the induced change in technology driven by environmental policy may (partially) undo the regulator's efforts. We also show that, given the presence of additional externalities, ITC may end up reducing the optimal stringency of environmental policy. Transparently, these 'unconventional' results arise under completely standard assumptions and are not just an intellectual curiosum.

The policy implications of our analysis are striking. That technology facilitates the working 
of environmental policy measures should not be taken for granted, as environmental policy might instead end up being less effective or more expensive, depending on how technology actually responds. Crucially, ambitious environmental policy efforts that rely on significant shifts in the existing technological paradigm need to be complemented by carefully designed measures to ensure that the incentives that emerge for investors are aligned with those of the social planner, in order to avoid environmental policy taking on an unexpected, paler shade of green.

In the rest of the paper, we build our investigation in steps. After a description of the model (Section 2) and the first-best outcome (Section 3), our analysis begins with an investigation of ITC within a framework with exogenous policy in Section 4 . In Section 5 , we shift our attention to a second-best environmental policy set-up. Finally, Section 6 discusses the relationship between our results and the existing literature, elaborates on some policy implications, and concludes.

\section{The model: firms, policy and consumers}

In our economy, a continuum of unit mass of identical firms produce the final good, $Y$, using technology, $H$, physical capital, $K$, and pollution, $P$. Output is strictly increasing in all (private) inputs. Output also increases with environmental quality, $N$, that enhances the productivity of all inputs, i.e. it increases total factor productivity (TFP). ${ }^{7}$ Throughout the paper we interpret $H$ as an intangible input - technology for short - used in production. It can be thought of as ideas, blueprints or patents purposefully developed via conscious efforts in the economy. It follows that $K$ should be thought of as all the tangible inputs i.e. physical capital - needed to embody these ideas and turn them into useful innovations (e.g. Solow, 1960; Intriligator, 1965). Environmental quality, $N$, is a 'public input' in the sense that aggregate pollution reduces environmental quality, but each individual firm has a negligible impact on the aggregate. Hence, the productivity effect of a cleaner environment is an externality. Thus, each firm $s \in[0,1]$ produces final output according to the following production function, ${ }^{8}$

$$
Y(s)=y(K(s), H(s), P(s), N),
$$

where environmental quality is normalized as the negative of aggregate pollution:

$$
N=-\int_{0}^{1} P(s) \mathrm{d} s .
$$

We assume that the marginal productivity of all inputs is strictly positive and decreasing, as customary. Given our assumption above that there exists a positive production externality

\footnotetext{
${ }^{7}$ The aggregate nature of our model implies a rather comprehensive understanding of what constitutes pollution in this context. In fact, anything that reduces environmental quality, $N$, represents pollution in our model, while environmental quality is anything that either boosts TFP or that provides utility to consumers. In this respect, $P$ is a broad indicator of the environmental and ecological footprint of human productive activities and should be thought of as encompassing polluting emissions and land use, as well as habitat and biodiversity loss, ecosystem services loss, and much more.

${ }^{8}$ Throughout the paper, we use capital letters to indicate variables and lower case ones denote functions. Moreover, we use subscripts to indicate partial derivatives, so that $\left.\partial z(X, Y) / \partial X=z_{X}, \partial^{2} z(X, Y)\right) / \partial X \partial Y=$ $z_{X Y}$
} 
from environmental quality, we let $y_{K N}>0, y_{H N}>0$, and $y_{P N}>0$. The empirical literature suggests that polluting inputs and capital are complements, ${ }^{9}$ which leads us to assume $y_{K P}>0$.

Several assumptions are possible in principle regarding the sign and relative magnitude of $y_{H K}$ and $y_{H P}$. In the interest of a concise presentation, in the main text we derive our results for the most interesting cases and address alternative situations in footnotes, as relevant. ${ }^{10}$ The first assumption we make in the main text is that technology is a gross substitute for pollution, all else equal. This assumption ensures that technology reduces the demand for polluting inputs, ceteris paribus: ${ }^{11}$

Assumption 1. Technology and pollution are gross substitutes, $y_{P H}<0$.

In the introduction, we argued that in the past a number of key new technologies increased demand for capital. Indeed, it seems undisputable that steam powered pumps and looms, internal combustion engines, plastics and fertilizers, jet planes and personal computer were all so successful in increasing the productivity of physical capital, that demand for pollution-intensive capital boomed. Thus, while in general not ruling out other possibilities, we are naturally led by this historical evidence to see $H$ and $K$ as complements in this context. We thus have our second assumption:

Assumption 2. Technology and physical capital are gross complements, $y_{H K}>0$.

The third restriction we impose in the main text ensures that capital becomes more productive if firms are allowed to pollute more, even taking into account the negative externality to production due to environmental quality, i.e.

Assumption 3. $y_{K P}>y_{K N}$.

Each firm can acquire technology and physical capital through costly investment. A higher level of either stock requires an increasingly larger amount of investment, $I(s)$ and $J(s)$, respectively. In the spirit of Arrow (1962) and Romer (1986), we assume that for both types of investment aggregate level affects the cost of investment for the individual firm in the form of knowledge spillovers. Since the firm's impact on aggregate investment is negligible, the effect of investment on costs through such spillovers constitutes an externality. Formally, the cost incurred by firm $s$ to acquire more technology is

$$
I(s)=i(H(s), \bar{H}),
$$

\footnotetext{
${ }^{9}$ That capital intensity positively correlates with pollution intensity is a commonly cited and used empirical regularity, e.g. Antweiler et al. (2001), Cole and Elliott (2003).

${ }^{10}$ In the interest of clarity, it should be noted here that none of Assumptions 12 or 3 is indispensable for our results, as is shown in footnotes 24 and 25

${ }^{11}$ This will become clearer below, see Lemma 3 Recall that new technologies make it possible to produce the same with less pollution as both $y_{H}$ and $y_{P}$ are positive. Whether new technologies make it attractive to reduce pollution, all else equal, depends on the sign of $y_{H P}$. If we assumed $y_{P H}>0$, innovation would trigger demand for polluting inputs. This is not unrealistic in certain contexts, e.g. improvements in oil drilling techniques, and one that would make it even more likely that ITC increased the cost of environmental policy - one of the central results of this paper. In what follows, we maintain Assumption 1 to be on the conservative side, and to allow for the possibility of 'green innovations.'
} 
where $\bar{H}$ is aggregate technology, i.e.

$$
\bar{H}=\int_{0}^{1} H(s) d s
$$

the corresponding function for physical capital is

$$
J(s)=j(K(s), \bar{K}),
$$

where $\bar{K}$ is the aggregate level of physical capital:

$$
\bar{K}=\int_{0}^{1} K(s) d s .
$$

Our monotonicity and convexity assumptions above imply that $i_{H}>0$ and $i_{H H}>0$, as well as $i_{K}>0$ and $i_{K K}>0$. As regards knowledge spillovers, two alternative situations are possible in principle. First, the learning-by-doing case, where aggregate investment reduces both marginal and total investment cost and $i_{\bar{H}}<0$ and $i_{H \bar{H}}<0$, for example. Second, the congestion case, where the opposite happens, e.g. due to patent races or fishing-out (cf. Jones, 1995). In this case $i_{\bar{H}}>0$ and $i_{H \bar{H}}>0$. In the interest of brevity, in the rest of the paper we only focus on the learning-by-doing case: ${ }^{12}$

Assumption 4. $i_{\bar{H}}<0, i_{H \bar{H}}<0$, and $i_{H \bar{H}}+i_{\bar{H} \bar{H}}<0$; similarly, $j_{\bar{K}}<0, j_{K \bar{K}}<0$, and $j_{K \bar{K}}+j_{\bar{K} \bar{K}}<0$.

To ensure a well defined equilibrium, we additionally need to rule out cases where the external effects are too strong, to this end we assume the following: ${ }^{13}$

Assumption 5. $i_{H H}+i_{H \bar{H}}-y_{H H}-\frac{y_{H K} y_{K H}}{j_{K K}+j_{K \bar{K}}-y_{K K}}>0$.

Each firm chooses the level of capital, technology, and pollution to maximize its profits, taking into account the regulations it faces. Regulation consist of a price on pollution equal to $\tau$ - which, depending on the policy instrument, can be either an explicit pollution tax, or the price of pollution permits under a cap and trade system ${ }^{14}$ - and subsidies equal to $\sigma$

\footnotetext{
${ }^{12}$ The last assumption in each set of inequalities simply assures that the gains from experience do not vanish with the size of the economy. These assumptions are satisfied by common specifications like the Cobb-Douglas, where $i(H, \bar{H}) \propto H^{\eta} \bar{H}^{\psi}$ with $\psi<0<\eta+\psi-1$, for example, or the quadratic, in which case $i(H, \bar{H}) \propto(H+\psi \bar{H})^{2}$ with $-1<\psi<0$.

${ }^{13}$ The positiveness of the expression in Assumption 5 is required for the stability of the symmetric Nash equilibrium. If the expression were negative, which would arise for sufficiently strong learning by doing effects $\left(i_{H \bar{H}}\right.$ sufficiently negative), an arbitrary small increase in investment by some firms (akin to a "tremble" in game theoretical parlance) would trigger sufficient spillovers to other firms for them to increase investment as well, without ever returning to the original symmetric equilibrium. Full details of the formal argument are available from the authors upon request.

${ }^{14}$ If we let $\bar{P}(s)$ be the permits allocated to firm $s$ and $\bar{P}=\int_{0}^{1} \bar{P}(s) d s$ the total amount of permits in the market, the assumption that firms are identical implies that, in equilibrium, $P(s)=P=\bar{P}$, for each $s$. This has the further implication that $\mathrm{d} \bar{P}=\mathrm{d} P$ : any tightening of the aggregate cap translates into an identical reduction in emissions for each individual firm. For economy of exposition, from now on we refer to a tightening of the cap directly as a reduction in $P$, rather than in $\bar{P}$.
} 
and $\theta$ for each unit of technology or physical capital it invests in, respectively. ${ }^{15}$ We assume that further distortions are avoided by imposing that any revenue from taxation or from the auctioning of permits is lump-sum rebated to households.

The profits of firm $s$ are given by: ${ }^{16}$

$$
\Pi(s)=y(K(s), H(s), P(s), N)-i(H(s), \bar{H})-j(K(s), \bar{K})+\sigma H(s)+\theta K(s)-\tau P(s),
$$

where we normalize the price of the final good to 1 , so that $y(\cdot)$ denotes revenue.

From our assumption that all firms are identical, it follows that they will be symmetric in equilibrium, so that we can drop the firm indicator in what follows. In the symmetric equilibrium, environmental quality and aggregate investment in the two types of capital see (2), (4), and (6) - take the following simple forms:

$$
N=-P, \bar{H}=H, \text { and } \bar{K}=K
$$

Our representative consumer derives utility from her consumption of the final good, and from her enjoyment of the natural environment. Formally, we write

$$
U=u(C, N ; \phi)
$$

where $C$ is consumption, i.e. the amount of aggregate output net of investment costs,

$$
C=Y-I-J
$$

We conform to standard assumptions by letting $u_{z}>0, u_{z z}<0$, for each input $z=C, N$, and $u_{C N}=u_{N C} \geq 0$. We use $\phi$ in the utility function to parameterize the relative preference for environmental quality. An increase in $\phi$ raises the marginal willingness to pay for environmental quality,

$$
\omega(C, N ; \phi) \equiv \frac{u_{N}(C, N ; \phi)}{u_{C}(C, N ; \phi)}
$$

and thus represents a greening of preferences. ${ }^{17}$

\footnotetext{
${ }^{15}$ We model support to investment as subsidies per unit of capital, be it technology, $H$, or physical capital, $K$. Alternatively, one could consider a subsidy per unit of investment cost, which would complicate the analytical expressions without changing the results. Notice, moreover, that in principle $\sigma$ and $\theta$ might well need to correct for a congestion externality (i.e. a negative knowledge spillover), in which case they would become negative subsidies, i.e. taxes.

${ }^{16}$ Notice that we have a market with homogenous output and price taking firms. In equilibrium, positive profits accrue due to an implicit fixed factor, e.g. managerial talent. Alternatively, we could have assumed monopolistic competition with profits due to product differentiation. This is the usual modelling practice in the endogenous growth literature. As long as firms are symmetric, no substantial changes would arise in the conclusions, although the results would be complicated by the additional externality stemming from monopolistic price setting.

${ }^{17}$ We assume that $\omega_{C}>0, \omega_{N}<0$. Moreover, we normalizing $\omega_{\phi}$ to 1 such that we can conveniently express the preference shift mentioned in the main text as $\mathrm{d} \phi=\left.\mathrm{d} \omega\right|_{\mathrm{d} C=\mathrm{d} N=0}>0$.
} 


\section{Solving the model: the first-best}

In the first-best equilibrium, the social planner chooses levels of $H, K$, and $P$ to maximize the representative agent's utility subject to the constraints represented by the available technology (1) and by the natural environment (2). At the optimum, the three types of externalities discussed above are all correctly internalized.

The optimal level of investment in technology, $H$, is obtained when the marginal productivity of any addition to the stock is exactly offset by the increase in the cost of investment, net of the cost savings due to learning-by-doing, i.e.

$$
y_{H}=i_{H}+i_{\bar{H}} .
$$

Similarly, for physical capital, $K$, we have:

$$
y_{K}=j_{K}+j_{\bar{K}}
$$

Finally, the optimal level of pollution emerges when, at the margin, any increase in output from the emission of a further unit of pollution is just compensated by the productivity losses and the decrease in utility arising from the additional deterioration of environmental quality. Formally,

$$
y_{P}=y_{N}+\omega .
$$

In a regulated market equilibrium the representative firm chooses physical capital, technology and pollution to maximize its profits, see (7). The equilibrium satisfies the following first-order conditions,

$$
\begin{gathered}
y_{H}=i_{H}-\sigma, \\
y_{K}=j_{K}-\theta, \\
y_{P}=\tau,
\end{gathered}
$$

where $\sigma, \theta$ and $\tau$ are the subsidies to the different types of investment and the mandated price of pollution discussed in section 2

From (12)-(14), it is immediate to see that the first-best outcome discussed above can be decentralized as a Nash equilibrium provided that the investment subsidies and the Pigouvian tax are given by:

$$
\begin{gathered}
\sigma^{*} \equiv-i_{\bar{H}}, \\
\theta^{*} \equiv-j_{\bar{K}}, \\
\tau^{*} \equiv y_{N}+\omega .
\end{gathered}
$$

While the first-best policy that simultaneously satisfies (18)- 20) is a useful benchmark for our analysis, it is hardly ubiquitous. Indeed, in reality much of the environmental policy debate refers to the introduction or the strengthening of pollution reducing measures, as well as the phasing out of ill-designed subsidies. For this reason, from now on we assume 
that the level of the pollution tax (or, equivalently, of the cap) is exogenously fixed at some arbitrary level lower (higher, respectively) than the one in (20). We further assume that technology is under-provided at the initial equilibrium, whereas physical capital is overprovided. In short, we make the following assumptions:

Assumption 6. The policy instruments in initial equilibrium satisfy $\tau<\tau^{*}, \sigma<\sigma^{*}$, and $\theta>\theta^{*}$.

This assumption realistically implies that there are reasons to advocate a tighter environmental policy, that in the market equilibrium firms underinvest in technology relative to the social optimum, and that subsidies exist that make polluting inputs 'too cheap' in the market equilibrium.

In this context, we will focus on studying the impact of a marginal tightening of environmental policy. Such a policy intervention is formally given by either an increase in the tax rate $\mathrm{d} \tau>0$, or by a reduction of the cap, i.e. $\mathrm{d} P<0$. In later sections, as our focus shifts to endogenous policy, we allow the consumers' willingness to pay for environmental quality to determine the environmental tax (or cap). In such situations, our thought experiment becomes one whereby preferences become greener - i.e. we study what happens when the marginal willingness to pay for environmental quality increases - and we investigate an increase in $\phi$ (see the discussion in Section 2, and footnote 17).

It is worth emphasizing at this stage that in what follows our aim is to gauge the impact of ITC. To isolate the effect of technical change, we then compare outcomes under exogenous technology - i.e. situations where changes in policy do not affect the level of $H$ - and outcomes in which $H$ is, instead, allowed to endogenously adjust to changes in policy - i.e. the ITC case. In the interest of clarity, it is useful to write the relevant equilibrium relationships as functions of the environmental variable, $P$, and the key endogenous variable of interest, $H$. Using the equilibrium definitions of $N, \bar{H}$, and $\bar{K}$ in (8), and substituting them into (16), we see immediately that the equilibrium level of physical capital can be written in terms of $P$ and $H$ only, as: ${ }^{18}$

$$
y_{K}(K, H, P,-P)-j_{K}(K, K)+\theta=0 \Rightarrow K=\widetilde{k}(H, P) .
$$

Using this expression and substituting the equilibrium values of $N$ and $\bar{H}$ into the first-order conditions (15) and (17), we can fully characterize each firm's choices in the symmetric Nash equilibrium purely in terms of $H$ and $P$ as follows:

$$
\begin{gathered}
\underbrace{y_{H}(\widetilde{k}(H, P), H, P,-P)-i_{H}(H, H)+\sigma}_{\tilde{r}(H, P)}=0, \\
\underbrace{y_{P}(\tilde{k}(H, P), H, P,-P)}_{\widetilde{m}(H, P)}=\tau .
\end{gathered}
$$

In the expressions above, $\widetilde{r}$ is the (excess) marginal return to investment in $H$, whereas $\widetilde{m}$ is the firm's marginal cost of pollution abatement (MAC), defined as the loss in output due to a marginal reduction in pollution, taking as given all the other inputs to production.

\footnotetext{
${ }^{18}$ Throughout the paper we will add a tilde “ " on a function symbol to highlight the fact that the variable of interest depends, in a symmetric equilibrium, on $P$ and $H$ only.
} 


\section{Induced technical change and exogenous environmen- tal policy}

We now begin our analysis of the role of ITC for the cost of environmental policy, starting with the workhorse model of environmental economics, i.e. a set-up with exogenous policy. Within this framework, we analyze the impact of a marginal tightening of environmental policy with and without induced technological change. As explained above, our aim is to contrast the exogenous technology equilibrium with the ITC one.

\subsection{A marginal tightening of environmental policy}

We start from equation (23), which describes the equilibrium relationship between the level of pollution and its price, for a given level of technology. Totally differentiating this equation, and rearranging terms, we get the following expression: ${ }^{19,20}$

$$
\frac{\mathrm{d} \tau}{\mathrm{d} P}=\widetilde{m}_{P}+\underbrace{\widetilde{m}_{H} \frac{\mathrm{d} H}{\mathrm{~d} P}}_{I T C}<0 .
$$

This equation separates changes in the marginal cost of abatement that occur as pollution changes, i.e. movements along the MAC curve, from changes arising as a consequence of changes in technology, i.e. shifts of the MAC curve itself. As indicated, the second term thus captures the effect of induced technical change. This component is traditionally assumed to be negative in the literature, so that the MAC curve shifts down as new technology is adopted. ${ }^{21}$ This, however, turns out not to be the case in our framework where the reverse shift emerges quite naturally. Before discussing this point further, however, we need to take a closer look at the impact of ITC on the MAC.

The ITC term is itself composed of two parts, $\widetilde{m}_{H}$, which gauges the impact of changes in technology on the marginal cost of pollution abatement, and $\mathrm{d} H / \mathrm{d} P$, which instead captures the impact of changes in pollution on the stock of technology. To make some inroads into understanding the first of the two, we partially differentiate (23) with respect to $H$ and use (21) to get:

$$
\widetilde{m}_{H}=y_{P H}+y_{P K} \underbrace{\left(\frac{y_{K H}}{j_{K K}+j_{K \bar{K}}-y_{K K}}\right)}_{\widetilde{k}_{H}} .
$$

The first term at the right-hand side of this expression informs us that, given our assumption that pollution and technology are gross substitutes, the direct effect of an increase in the technology stock is to reduce the marginal cost of pollution reductions. The second

\footnotetext{
${ }^{19}$ Note that either the price or the quantity of pollution can be exogenously given in this context, depending on whether we assume a regulator using a tax or a cap $\&$ trade system.

${ }^{20}$ The negativity of the expression below is directly implied by the necessary second-order conditions for the profit maximization problem faced by firms.

${ }^{21}$ This case is captured in both panels of Figure 1 below by the dashed lines marked $M A C^{S}$. Well know references in the literature that make this assumption include Milliman and Prince (1989), Goulder and Mathai (2000), Requate and Unold (2003), Jaffe et al. 2003), Goulder (2004).
} 
term, however, highlights an additional channel through which changes in technology affect the cost of pollution reduction. Since $\widetilde{m}$ is also a function of $K$, the MAC is affected by changes in the physical capital stock that occur as a consequence of changes in technology $\left(\widetilde{k}_{H}\right)$. Equation 25 informs us that these induced changes in $K$ may offset, and even reverse, the direct effect of $H$ on the MAC. This possibility arises whenever the degree of complementary between technology and physical capital is sufficiently large. We characterize a situation where the MAC curve shifts upwards following an increase in technology investment as a case of brown technology. When the MAC curve shifts downwards as technology improves, instead, we talk of technology being green. This latter case arises when the two types of investment are not sufficiently complementary for the sign of $\widetilde{m}_{H}$ to be positive. ${ }^{22}$ Formally, we have:

Lemma 1. In the model discussed above, technology is brown whenever

$$
\tilde{m}_{H}>0 \Leftrightarrow y_{H K}>-\frac{y_{P H}}{y_{P K}}\left(j_{K K}+j_{K \bar{K}}-y_{K K}\right),
$$

and green otherwise.

Proof. Using (25), simply solve $\widetilde{m}_{H}>0$ in terms of $y_{H K}$ to get the expression above.

So far we have shown that, under perfectly plausible assumptions, the MAC may increase rather than decrease, when technology is allowed to adjust. This result, which goes against the assumptions commonly made in the literature, is not novel in the sense that others have made the case for an increasing MAC (e.g. Amir et al. 2008, Baker et al. 2008, Bauman et al. 2008, Heal and Tarui 2010, Perino and Requate, 2012). ${ }^{23}$ Our modelling of brown technology differs from these other contributions, however, in that in our framework new technology is always green per se, since $y_{P H}<0$. Technological change turns brown due to possible complementarity between technology and physical capital, which leads to the environmental impacts - see the discussion leading up to Assumption 2.

The second term in the expression of the ITC effect in (24), $\mathrm{d} H / \mathrm{d} P$, gauges the impact of changes in pollution on investment in technology. At the initial equilibrium, each firm sets the level of investment in $K$ and $H$ according to the first-order conditions (15) and 16). Totally differentiating these two equations, recalling (8), and using the resulting expressions to solve for $\mathrm{d} H / \mathrm{d} P$, we find:

$$
\frac{\mathrm{d} H}{\mathrm{~d} P}=\zeta \underbrace{\left[\left(y_{H P}-y_{H N}\right)+\frac{y_{H K}}{j_{K K}+j_{K \bar{K}}-y_{K K}}\left(y_{K P}-y_{K N}\right)\right]}_{\widetilde{r}_{P}},
$$

\footnotetext{
${ }^{22}$ Obviously, when Assumption 2 is violated and technology and physical capital are substitutes rather than complements, the MAC can only decrease with additional technology creation, and technology is always green. When (only) Assumption 1 is violated, technology is always brown. When both Assumptions 1 and 2 are violated, again technology can be either brown or green.

${ }^{23}$ All the papers cited show that MAC curves for old and new technologies may actually cross, implying that the same innovation may be either green or brown, depending on the range of abatement, which clearly depends on the policy stringency. This is particularly relevant when, as in Perino and Requate (2012) for example, the evaluation of the effect of environmental policy is performed against a 'no-policy' counterfactual. In the present paper, however, we only deal with marginal changes in policy stringency, so we disregard this aspect and classify technologies as either (locally) green or brown.
} 
where we let $\zeta \equiv\left[\left(i_{H H}+i_{H \bar{H}}-y_{H H}\right)-\frac{y_{H K} y_{K H}}{j_{K K}+j_{K \bar{K}}-y_{K K}}\right]^{-1} \geq 0$, see Assumption 5 . In this expression, $\widetilde{r}_{P}$ is the change in the rate of return to investment in technology brought about by a reduction in pollution. The first term in the square bracket in 26 illustrates that the decision to invest in technology is driven by the increased demand for $H$ linked to the decrease in pollution and the associated improvement in environmental quality. Intuitively, more stringent environmental policy crowds in additional investment in technology, its substitute factor. This is not the whole story, however, as investment in technology is also affected by changes in the stock of physical capital - the second part of the bracket in (26). Under Assumption 3 investment in physical capital is reduced along with any reduction in pollution. Since capital and technology are complements, technology accumulation is reduced via this channel. Provided that the complementarity between $K$ and $H$ is sufficiently strong, environmental policy ends up crowding out investment in technology, which runs counter to traditional tenets. The following lemma formalizes this discussion. ${ }^{24}$

Lemma 2. A marginal tightening of environmental policy crowds out investment in technology whenever

$$
\widetilde{r}_{P}>0 \Leftrightarrow y_{H K}>-\frac{y_{H P}-y_{H N}}{y_{K P}-y_{K N}}\left(j_{K K}+j_{K \bar{K}}-y_{K K}\right)>0 .
$$

Proof. Crowding out as a consequence of environmental policy requires $\mathrm{d} H / \mathrm{d} P>0$, the statement of the Lemma follows immediately from using (26) and recalling Assumption 3.

In our discussion so far we have explained how, in the context of a marginal tightening of exogenous environmental policy, the overall effect of ITC depends on the colour of technology, i.e. whether technology is green or brown, and on whether environmental policy crowds technology in or out. From (24), it is clear that whenever the ITC term is positive, technological change proves pollution-saving, in the sense that - consistently with the dominant view - it reduces the marginal cost of pollution abatement. Interestingly, however, the possibility that technical change be pollution-using, i.e. that it might lead to an increase in the marginal abatement cost - a situation ruled out by most of the literature - is perfectly possible in our framework. ${ }^{25}$

Lemma 3. Induced Technical Change is pollution-using whenever

$$
\widetilde{r}_{P} \widetilde{m}_{H}<0 .
$$

This can only happen when brown technology is crowded in, which requires,

$$
-\frac{y_{H P}}{y_{K P}}\left(j_{K K}+j_{K \bar{K}}-y_{K K}\right)<y_{H K}<-\frac{y_{H P}-y_{H N}}{y_{K P}-y_{K N}}\left(j_{K K}+j_{K \bar{K}}-y_{K K}\right) .
$$

\footnotetext{
${ }^{24}$ Lemma 2 holds for Assumptions 1-3. The possibility of crowing out also obtains when technology and physical capital are substitutes (i.e. when Assumption 2 is reversed). The condition under which crowding out arises becomes: $y_{H K}\left(y_{K P}-y_{K N}\right)>-\left(y_{H P}-y_{H N}\right)\left(j_{K K}+j_{K \bar{K}}-y_{K K}\right)$. With $y_{H K}<0$, crowding out requires $y_{K P}<y_{K N}$, i.e. the productive externality associated with environmental quality be strong enough to reverse the sign in Assumption 3

${ }^{25}$ When technology and physical capital are substitutes rather than complements (i.e. when Assumption 2 is reversed), the possibility emerges that pollution-using technical change might result from the crowding out of green technology. Just like the case discussed in footnote 24 above, however, this result only obtains when the productive externality associated with environmental quality is sufficiently strong, i.e. when $y_{K P}<y_{K N}$ (and Assumption 3 is reversed).
} 
Proof. The proof follows immediately from Lemma 1 and 2 .

The lemma highlights the potentially surprising conclusion that environmental policy may lead firms to make investment decisions that imply an increase in pollution. In fact, this outcome is less surprising when one considers that as the price of pollution increases, it depresses the returns to pollution-using technologies and at the same time, it boosts them through the indirect effect of the improved environmental quality. Since the productivity effect of environmental quality is an externality - firms do not internalize the effect of their decisions on environmental quality and productivity - it may still be individually rational for firms to respond to high pollution prices (or better to the combination of higher prices and higher productivity) by investing in ways that, in equilibrium, increases pollution.

The fact that the marginal cost of pollution abatement might increase under induced technical change has profound implications for the analysis of environmental policy. In fact, when induced technological change proves pollution-using, the traditional conclusion that ITC makes environmental policy less expensive/more effective is turned on its head. Figure 1. illustrates this point. In both panels, the initial equilibrium, point $A$ in the graphs, is characterized by a pollution price equal to $\tau_{0}$, and by a level of pollution given by $P_{0}$. The slope of the MAC curve at the initial equilibrium is given by the expression in (24). Since we only focus on marginal changes, we can ignore second order effects that might change the slope of the $M A C$ curve and simplify the diagram by drawing straight lines.

Consider how environmental policy operates when technology is completely exogenous , i.e. let the ITC term be zero. In this case, either an exogenous increase in the pollution charge from $\tau_{0}$ to $\tau_{1}$, say, or a reduction of the number of permits in the cap-and-trade system from $P_{0}$ to $P_{1}$ produce the same outcome, namely a new equilibrium which obtains at a point like $X$, along the $M A C$ curve.

Under ITC, however, the outcome depends on the interaction between the nature of technology, the firm's incentives to invest, and the type of instrument chosen by the regulator. The standard case discussed in the literature features pollution-saving technical change. As discussed above, in this case a more stringent environmental policy induces the crowding in of green technology, and the $M A C$ curve shifts down to $M A C^{S}$, where the $S$ superscript is for 'saving'. The exact new equilibrium level depends on the choice of the instrument. Under exogenous taxation - see Figure 1 (a) - as the tax rises to $\tau_{1}$ pollution falls more than in the exogenous technology case, and the new equilibrium is reached at point $G$. Figure 1 (b), instead, presents the equilibrium emerging when the regulator resorts to tradable emission permits. At the new equilibrium, point $G^{\prime}$, the pollution level is the same but the permit price is lower under ITC, since $\tau_{G}<\tau_{1}$.

Contrast this outcome, however, to what happens when environmental policy crowds in investments in brown technology. This has the effect of making pollution more productive and it raises the opportunity cost of curbing it. The net effect is that the $M A C$ curve shifts upwards. The equilibrium $M A C$ schedules under ITC - the dashed lines in the graphs marked $M A C^{U}$, for 'using' - are now higher than when technology doesn't adjust. When the regulator uses a pollution charge, as in Figure 11(a), less pollution reduction occurs at the new equilibrium (at point $B$ ), relative to the exogenous technology case, indicating a higher opportunity cost of emissions reductions. When the regulator chooses a cap \& trade 


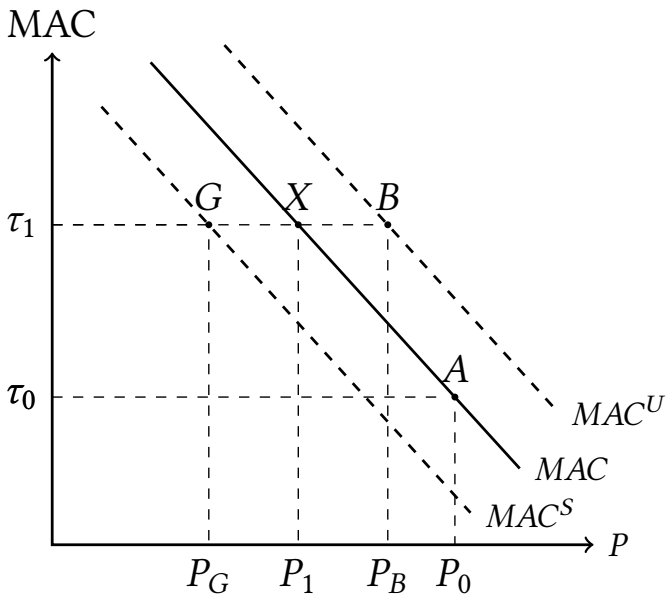

(a) an emission charge

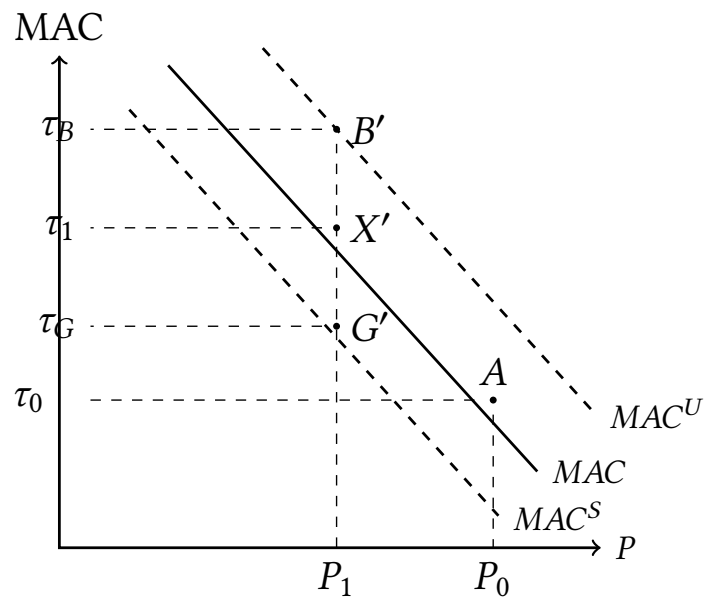

(b) a cap \& trade system

Figure 1: Exogenous policy under induced technological change

system, as in Figure 11(b) the permit price increases more than in the exogenous technology scenario (to point $B^{\prime}$ ). Since in the symmetric equilibrium $\tau$ equals the marginal cost of pollution reduction, induced pollution-using technical change makes environmental policy more costly.

The discussion above can be summarized as follows:

Proposition 1. Under exogenous policy, induced pollution-using technical change leads to...

i. ... a larger increase in the private marginal cost of environmental policy after a marginal tightening of the cap on pollution;

ii. ... a smaller pollution reduction following a marginal increase in the pollution charge.

Proof. In the text above.

This result presents a very different picture of the role of ITC from what is commonly discussed in the literature and sets our paper quite apart from the existing body of technology as it presents a rather more pessimistic view of the role of technology in solving environmental challenges. ${ }^{26}$

\footnotetext{
${ }^{26}$ In a related contribution, Perino and Requate (2012) find that an increase in the stringency of environmental policy may result in a reduced rate of technology adoption by firms for a sufficiently high level of stringency. Since their focus is on technology adoption and the dynamic efficiency of environmental policy, they compare their outcomes to a benchmark economy without policy - see Footnote 23 . It follows that the introduction of environmental policy can increase aggregate emissions in their framework. In the present paper, however, our emphasis is on the role of ITC on the cost of policy, and we only focus on marginal changes in the stringency of existing policy. As a consequence, a scenario such as theirs cannot emerge here, and environmental policy always reduce pollution emissions.
} 


\subsection{Welfare implications}

Proposition 1 presents the implications of ITC for the effectiveness and the cost of exogenous environmental policy. The natural next step is to investigate the consequences of ITC for the welfare gains due to a tightening of environmental policy. It is easiest in this context to start with a reduction in the emission cap, as in this case the introduction of ITC does not affect the environmental integrity of the policy change, and comparisons across regimes are more straightforward.

Consider the utility function in (9), substitute for the level of consumption using the market clearing condition 10 and express the resulting expression as a function of $P$ and $H$ only using the symmetric equilibrium conditions in (8), and (21). Totally differentiating the resulting expression and recalling the first-order conditions (16)-(17), as well as the definitions of the first-best policy levels (18) and (20), we are able to get the following expression for the change in welfare in terms of consumption equivalents:

$$
\frac{\mathrm{d} U}{u_{C}}=-\{\left[\left(\tau^{*}-\tau\right)-\left(\theta^{*}-\theta\right) \widetilde{k}_{P}\right]-\underbrace{\left[\left(\sigma^{*}-\sigma\right)+\left(\theta^{*}-\theta\right) \widetilde{k}_{H}\right] \widetilde{\zeta}_{P}}_{\text {ITC }}\} \mathrm{d} P,
$$

where $\widetilde{k}_{P} \equiv \frac{y_{K P}-y_{K N}}{j_{K K}+j_{K \bar{K}}-y_{K K}}>0$ and $\widetilde{k}_{H}$ is defined in 25 .

The expression above illustrates the channels through which a reduction in pollution affects welfare. Moving from left to right across terms at the right-hand side, we see, first of all, that a drop in pollution directly reduces the welfare costs from the environmental externality: given that the initial price of pollution is suboptimally low, a marginal reduction in pollution is bound to improve welfare. Next, since physical capital decreases as pollution declines (recall that $\widetilde{k}_{P}>0$ ), welfare must improve: the over-supply of physical capital due to the excessive subsidies - see Assumption 6- is moderated by the drop in pollution. Finally, the ITC effect is captured by the second term in the curly bracket. A drop in pollution affects welfare both via its direct effect on $H$, captured by $\widetilde{r}_{P}$, and its indirect effect on $K$, gauged by $\widetilde{k}_{H} \widetilde{r}_{P}$. Changes in pollution affect welfare positively in as far as it increases investment in technology. If the drop in pollution leads to a reduction in physical capital via the induced changes in $H$, however, welfare gains are reduced.

Things are more complicated when we turn to considering environmental policy conducted via a tax instrument. In this case the channels mentioned above interact with the impact of ITC on the effectiveness of the tax discussed in Proposition 1. Indeed, in this context any given increase in the tax has a different impact on the equilibrium level of pollution under ITC than when technology is exogenously given. To see this, simply multiply and divide the right-hand side of equation (27) by $\mathrm{d} \tau$, and use (24) to substitute for $\mathrm{d} P / \mathrm{d} \tau$ to get:

$$
\frac{\mathrm{d} U}{u_{C}}=-\{\left[\left(\tau^{*}-\tau\right)-\left(\theta^{*}-\theta\right) \widetilde{k}_{P}\right]-\underbrace{\left[\left(\sigma^{*}-\sigma\right)+\left(\theta^{*}-\theta\right) \widetilde{k}_{H}\right] \widetilde{\zeta r_{P}}}_{I T C}\}(\widetilde{m}_{p}+\underbrace{\widetilde{m}_{H} \zeta \widetilde{r}_{P}}_{I T C})^{-1} \mathrm{~d} \tau .
$$

The additional term marked ITC emphasizes precisely the fact that under a pollution charge ITC influences welfare also via its impact on the effectiveness of the environmental tax. The 
following proposition summarizes the possible welfare outcomes for each type of instrument:

Proposition 2. Under exogenous policy, induced technical change...

i. ...implies smaller welfare gains from a marginal tightening of the cap on pollution, whenever

$$
\widetilde{r}_{P}<0 \cap \widetilde{k}_{H}>-\frac{\left(\sigma^{*}-\sigma\right)}{\left(\theta^{*}-\theta\right)}
$$

or,

$$
\widetilde{r}_{P}>0 \cap \widetilde{k}_{H}<-\frac{\left(\sigma^{*}-\sigma\right)}{\left(\theta^{*}-\theta\right)} .
$$

ii. ...implies smaller welfare gains from a marginal increase in the pollution tax, whenever

$$
\widetilde{r}_{P}<0 \cap \widetilde{k}_{H}>-\frac{\left(\sigma^{*}-\sigma\right)}{\left(\theta^{*}-\theta\right)}-\frac{\widetilde{m}_{H}}{\widetilde{m}_{P}} \frac{\left[\left(\tau^{*}-\tau\right)-\left(\theta^{*}-\theta\right) \widetilde{k}_{P}\right]}{\left(\theta^{*}-\theta\right)},
$$

or,

$$
\widetilde{r}_{P}>0 \cap \widetilde{k}_{H}<-\frac{\left(\sigma^{*}-\sigma\right)}{\left(\theta^{*}-\theta\right)}-\frac{\widetilde{m}_{H}}{\widetilde{m}_{P}} \frac{\left[\left(\tau^{*}-\tau\right)-\left(\theta^{*}-\theta\right) \widetilde{k}_{P}\right]}{\left(\theta^{*}-\theta\right)} .
$$

Proof. See Appendix A

Generally speaking, the statements in the proposition are quite intuitive: under Assumption 6 the crowding in of investment in technology is a positive consequence of environmental policy, and one would indeed expect that ITC compounds welfare gains when $\widetilde{r}_{P}<0$. These positive effects may, however, be reversed in the presence of a very strong inducement of investment in physical capital. Conversely, in the presence of crowding out, ITC would be expected to reduce welfare by worsening the under-provision of technology in the economy. In this case, the reduction in physical capital investment due to the complementarity between technology and physical capital might more than compensate for this negative impacts, again giving rise to mixed results.

Going beyond this general intuition and in order to grasp the second part of the proposition, it is necessary to take into account that when policy is implemented via a price instrument, ITC has the potential to limit the effectiveness of environmental policy when technical change is pollution-using (see Proposition 1). To see what this implies in terms of welfare changes, consider the first claim in part ii. of Proposition 2 above. In this crowding out scenarion, ITC is pollution-using when technology is brown, i.e. when $\widetilde{m}_{H}>0$ (see Lemma 1). Thus, pollution-using technical chance compounds the negative effects of crowding in physical capital discussed above. The condition presented in the proposition, reflects this as when $\widetilde{m}_{H}>0$ the threshold for $\widetilde{k}_{H}$ beyond which ITC represents a drag on welfare becomes easier to attain. On the contrary, when technological change is pollution-saving which, in the case of crowding in requires green technology (i.e., $\widetilde{m}_{H}<0$ ) - ITC boosts the environmental benefits from any increase in the pollution charge, and ITC tends to increase welfare, adding to the positive effect of a drop in physical capital. This is evident in the first 
expression in part ii. above, which shows that, in this case, the requirements for ITC to contribute negatively to welfare become more stringent (recall that $\widetilde{m}_{P}<0$ ). ${ }^{27}$

We conclude this discussion by remarking that our results indicate that ITC may reduce the welfare benefits from environmental policy under either types of technology - green or brown - and under either choice of policy instrument - quantity-based or price-based. Once again this suggests that the optimistic conclusions found elsewhere in the literature are a function of modelling and parametrization choices, rather than of more fundamental reasons.

\section{Endogenous policy under induced innovation}

Having discussed the behaviour of firms in the presence of environmental policy, we now turn to modelling the choice made by the environmental policy authority (the Environmental Protection Agency - EPA for short) of the 'best possible' policy. Realistically, we assume that the EPA attempts to maximize social welfare but is unable to choose investment policy, i.e. the investment subsidies are fixed. As a consequence, the investment externalities are not correctly internalized and a second-best situation arises where environmental policy is used to address both the environmental and investment externalities.

\subsection{The regulator's problem}

The EPA's objective is to maximize the utility of the representative agent, given in (9), subject to the technological, environmental, and financial constraints it faces - see equations (1), (2), and (10) respectively. In addition, the EPA needs to take into account that, once environmental policy is set, firms will choose their level of investment in both physical capital and technology according to their first-order conditions (15) and (16). In short, the EPA's maximization program reads:

$$
\begin{array}{rl}
\max _{P} & U=u(C, N ; \phi) \\
\text { s.t. } & C=y(H, K, P, N)-i(H, \bar{H})-j(K, \bar{K}) ; \\
& y_{K}=j_{K}-\theta ; \\
& y_{H}=i_{H}-\sigma .
\end{array}
$$

The first-order necessary condition for this problem is, plainly:

$$
y_{P}=y_{N}+\omega(C, N ; \phi)-\left(y_{H}-i_{H}-i_{\bar{H}}\right) \frac{\mathrm{d} H}{\mathrm{~d} P}-\left(y_{K}-j_{K}-j_{\bar{K}}\right) \frac{\mathrm{d} K}{\mathrm{~d} P} .
$$

Using our by now familiar approach, we express this equation as a function of $P$ and $H$ only. To do this, we first note that we can use the goods market equilibrium condition (10),

\footnotetext{
${ }^{27}$ A similar discussion holds for the case of crowding out, i.e. when $\widetilde{r}_{P}<0$, keeping in mind, however, that in this case pollution-using technical change requires green technology.
} 
together with the production and investment functions, (1), (3), and (5), and the symmetric equilibrium condition, (8), to rewrite consumption, $C$, as

$$
C=y(\widetilde{k}(H, P), H, P,-P)-i(H, H)-j(\widetilde{k}(H, P), \widetilde{k}(H, P)) \equiv \widetilde{c}(H, P) .
$$

Recalling the expression for $\omega(C, N ; \phi)$ in $(11)$, and using (8) along with (21), the first-order condition above becomes

$\underbrace{y_{P}(H, P)}_{m}=\underbrace{y_{N}(H, P)+\omega(\widetilde{c},-P ; \phi)}_{\tau^{*}}-\underbrace{\left[y_{K}(H, P)-j_{K}-j_{\bar{K}}\right]}_{\left(\theta^{*}-\theta\right)}\left(\widetilde{k}_{P}+\widetilde{k}_{H} \frac{\mathrm{d} H}{\mathrm{~d} P}\right)-\underbrace{\left[y_{H}(H, P)-i_{H}-i_{\bar{H}}\right]}_{\left(\sigma^{*}-\sigma\right)} \frac{\mathrm{d} H}{\mathrm{~d} P}$.

According to this expression, the (second-best) optimal level of pollution allowed by the EPA is such that the marginal cost of pollution abatement, $m$, equals the marginal benefit from pollution reduction, i.e. the marginal damage from pollution, at the right-hand side of the expression above. In the present context the social marginal damage of pollution differs from the first-best Pigouvian tax, $\tau^{*}$, as it additionally entails a correction that captures the distortionary effect of the remaining externalities. Correspondingly the second-best pollution price needed to decentralize the social optimum is, using 26) to substitute the ratios in the first-order condition,

$$
\tau^{S B} \equiv \tau^{*}-\left(\sigma^{*}-\sigma\right) \zeta \widetilde{r}_{P}+\left(\theta-\theta^{*}\right)\left(\widetilde{k}_{P}+\widetilde{k}_{H} \widetilde{\zeta}_{P}\right) .
$$

Given the existence of the imperfectly corrected externalities linked to capital accumulation the EPA sets the price of pollution taking into account the effect that environmental policy has on the firms' investment decisions. When environmental policy crowds in investment in technology, for example, the EPA optimally tends to set the price of pollution above the Pigouvian level. In this case the amelioration of the distortion connected to the sub-optimally low investment in $H$ compounds the environmental benefits, and a higher level of $\tau$ is warranted. The EPA, however, also needs to take into account that, in this context, a higher price for pollution, while alleviating the over-accumulation of physical capital directly, crowds in $K$ via its complementarity with technology. If a more stringent environmental policy on balance increases physical capital investment, the regulator is naturally led to re-focus environmental policy towards the correction of the physical capital externality and opts for a laxer environmental policy. Clearly, the relative strength of the crowding in/out of physical capital and technology determines the sign and magnitude of the second-best wedge, $\left(\tau^{S B}-\tau^{*}\right){ }^{28}$

In Section 4 we have shown that the presence of ITC affects firms' marginal costs of abatement - i.e. the supply of pollution abatement - beyond the traditional view that it necessarily decreases marginal costs. This is obviously relevant in the present context as it affects the optimal choice of pollution by the EPA by changing the left-hand side of the first-order condition above. The discussion in the previous paragraph suggests that ITC

\footnotetext{
${ }^{28}$ Formally, it is easy to show from $\left[30\right.$ that in the presence crowding in of $H$, i.e. when $\widetilde{r}_{P}<0$ the EPA naturally tends to impose a relatively more stringent environmental policy, unless the indirect crowding in of physical capital via the complementarity with technology proves too strong. In this case $\tau^{S B}-\tau^{*}>0$ requires $\widetilde{k}_{H}<\frac{\left(\sigma^{*}-\sigma\right)}{\left(\theta^{*}-\theta\right)}-\frac{\widetilde{k}_{P}}{\zeta \widetilde{r}_{P}}$. Conversely, when it is the crowding out of technology to prevail and $\widetilde{r}_{P}>0$, $\tau^{S B}-\tau^{*}>0$ requires $\widetilde{k}_{H}>\frac{\left(\sigma^{*}-\sigma\right)}{\left(\theta^{*}-\theta\right)}-\frac{\widetilde{k}_{P}}{\zeta \widetilde{r}_{P}}$.
} 
may also modify the demand for pollution abatement, captured by the right-hand side of the first-order condition. It follows that in the context of endogenous policy the role of ITC is much more pervasive than in the exogenous policy framework. This observation further underlines the relevance of our analysis in qualifying widespread misconceptions with respect to the role of ITC in environmental policy. We now turn our attention to the role of ITC in endogenous policy making.

\subsection{A marginal greening of preferences}

To investigate the role of ITC in the conduct of environmental policy in this second-best scenario, we let preference become 'greener' in the sense that environmental services become more valuable to consumers, and we analyze the endogenous change in environmental policy. This thought experiment parallels the exogenous marginal tightening of environmental policy that we have investigated in previous sections. Our goal is to compare changes in environmental quality in response to such a shock, with and without ITC. If, following a 'greening' of preferences, the level of pollution decreases less under ITC than in its absence, we can conclude that ITC makes environmental policy more costly to implement.

We start by rewriting the first-order condition that characterizes the second best using (26) and re-arranging terms as:

$$
m=\tau^{*}+\left(\theta-\theta^{*}\right) \widetilde{k}_{P}-\left[\left(\sigma^{*}-\sigma\right)-\left(\theta-\theta^{*}\right) \widetilde{k}_{H}\right] \widetilde{\zeta}_{P} .
$$

Formally, our experiment is to shock this expression via an increase in the relative preference for environmental quality, parameterized by $\phi$. Totally differentiating (31) and rearranging terms gives us the following expression for how a greening of preferences changes the optimal level of pollution: ${ }^{29}$

$$
\frac{\mathrm{d} P}{\mathrm{~d} \phi}=\frac{1}{\left(\widetilde{m}_{P}-\widetilde{\tau}_{P}^{*}+\widetilde{\theta}_{P}^{*} \widetilde{k}_{P}\right)+\zeta[\underbrace{\widetilde{m}_{H} \widetilde{r}_{P}-\widetilde{\tau}_{H}^{*} \widetilde{r}_{P}+\widetilde{r}_{P}\left(\widetilde{\theta}_{P}^{*} \widetilde{k}_{H}+\widetilde{\theta}_{H}^{*} \widetilde{k}_{P}+\zeta \widetilde{\sigma}_{H}^{*} \widetilde{r}_{P}+\zeta \widetilde{\theta}_{P}^{*} \widetilde{k}_{H} \widetilde{r}_{P}\right)}_{I T C}]} .
$$

As indicated, the terms multiplied by $\zeta$ jointly capture the role of ITC in determining the optimal level of environmental quality. A positive (respectively, negative) ITC term leads to a lower (higher) level of pollution relative to the exogenous technology case for any given change in preference, as stated in our concluding result:

Proposition 3. Following a marginal greening of preferences, induced technical change leads to $a$ smaller reduction in the second-best optimum level of pollution if and only if

$$
\widetilde{m}_{H} \widetilde{r}_{P}-\widetilde{\tau}_{H}^{*} \widetilde{r}_{P}+\widetilde{r}_{P}\left(\widetilde{\theta}_{P}^{*} \widetilde{k}_{H}+\widetilde{\theta}_{H}^{*} \widetilde{k}_{P}+\zeta \widetilde{\sigma}_{H}^{*} \widetilde{r}_{P}+\zeta \widetilde{\theta}_{P}^{*} \widetilde{k}_{H} \widetilde{r}_{P}\right)<0 .
$$

This happens under crowding-in, when:

$$
\frac{\omega_{C}\left[\left(\sigma^{*}-\sigma\right)+\left(\theta^{*}-\theta\right) \widetilde{k}_{H}\right]-\widetilde{\theta}_{P}^{*} \widetilde{k}_{H}-\widetilde{\theta}_{H}^{*} \widetilde{k}_{P}}{1+\zeta \widetilde{\sigma}_{H}^{*}+\zeta \widetilde{\theta}_{H}^{*} \widetilde{k}_{H}}<\widetilde{r}_{P}<0,
$$

\footnotetext{
${ }^{29}$ In deriving the expression in the text, we abstract from higher-order effects by suppressing all third order partial derivatives.
} 
and under crowding-out, when:

$$
0<\widetilde{r}_{P}<\frac{\omega_{C}\left[\left(\sigma^{*}-\sigma\right)+\left(\theta^{*}-\theta\right) \widetilde{k}_{H}\right]-\widetilde{\theta}_{P}^{*} \widetilde{k}_{H}-\widetilde{\theta}_{H}^{*} \widetilde{k}_{P}}{1+\zeta \widetilde{\sigma}_{H}^{*}+\zeta \widetilde{\theta}_{H}^{*} \widetilde{k}_{H}} .
$$

Proof. In Appendix A

While the mechanics behind this result are clear, our goal in the remaining of this section is to focus on the economic intuition. We first note here that $\widetilde{m}_{H} \widetilde{r}_{P}$ in the ITC term in (32) captures the impact of ITC on the marginal costs of abatement and determines the pollution-saving, or -using nature of technical change (see Lemma 3). The remainder of the term gauges the effect of ITC on the social marginal damage of pollution discussed in Section 5.1. More specifically, the term $\widetilde{\tau}_{H}^{*} \widetilde{r}_{P}$ captures the effect on the Pigouvian tax, whereas the third and final term measures the impact of ITC on the second-best wedge. Given this, it turns out that casting our discussion of the intuition behind Proposition 3 within the framework of the textbook marginal abatement cost/marginal damages graphs clarifies the issues and provides useful insights.

Figure 2 provides a graphical representation of condition (31). ${ }^{30}$ The MAC curves represent the marginal cost of abatement and captures the firm's willingness to pay for pollution, $m$ in (31). Each $M A C$ curve is drawn for a different level of technology. The $M D$ curves show the marginal damage of pollution, the right-hand side of equation (31) for a given level of $\phi$ and $H$. The second-best level of pollution obtains when, at the margin, the benefits from a further reduction in pollution are just offset by the increase in the costs of pollution abatement. This level is graphically identified by the intersection of the appropriate $M A C$ and $M D$ curves. The initial equilibrium is at point $A$, where the level of technology equals $H_{0}$, preferences have not yet shifted so that $\phi=\phi_{0}$, and the level of pollution is $P_{A}$.

Consider what the exogenous shift in preferences does to the equilibrium, ignoring for the moment the role of technological change. As $\phi$ increases to $\phi_{1}$ indicating a relative greening of societal preferences, the $M D$ curve shifts upwards since consumers are now more willing to pay for environmental quality. With given technology, the new equilibrium obtains at point $B$. As expected, the level of pollution is lower and environmental quality higher.

Let us now focus on how ITC modifies this picture. First of all, following the change in preferences, and the increased demand for environmental quality, firms adjust their level of investment in both technology and physical capital. This leads to a change in the (opportunity) cost of abatement. This aspect was analyzed at length in Section 4 and in particular in Lemma 3. Figure 2 captures the case where the $M A C$ curve shifts down due to pollutionsaving technical change, for example as a consequence of the crowding in of green technology. ${ }^{31}$ Not surprisingly, if we were to neglect any other impact of ITC, we would conclude

\footnotetext{
${ }^{30}$ The figure distinguishes between the model with induced technical change (the heavier solid lines) and the model in which the level of investment doesn't adjust following a change in preferences (the lighter lines). In principle, the two models would generate different initial equilibrium levels of pollution. To facilitate the comparability between the two models and to isolate the effect of ITC, however, we assume an appropriate calibration of the two models such that they share the same initial equilibrium.

${ }^{31}$ As discussed in Section 4 a downward shift of the MAC curve might just as well be the result of the crowding out of brown technology.
} 


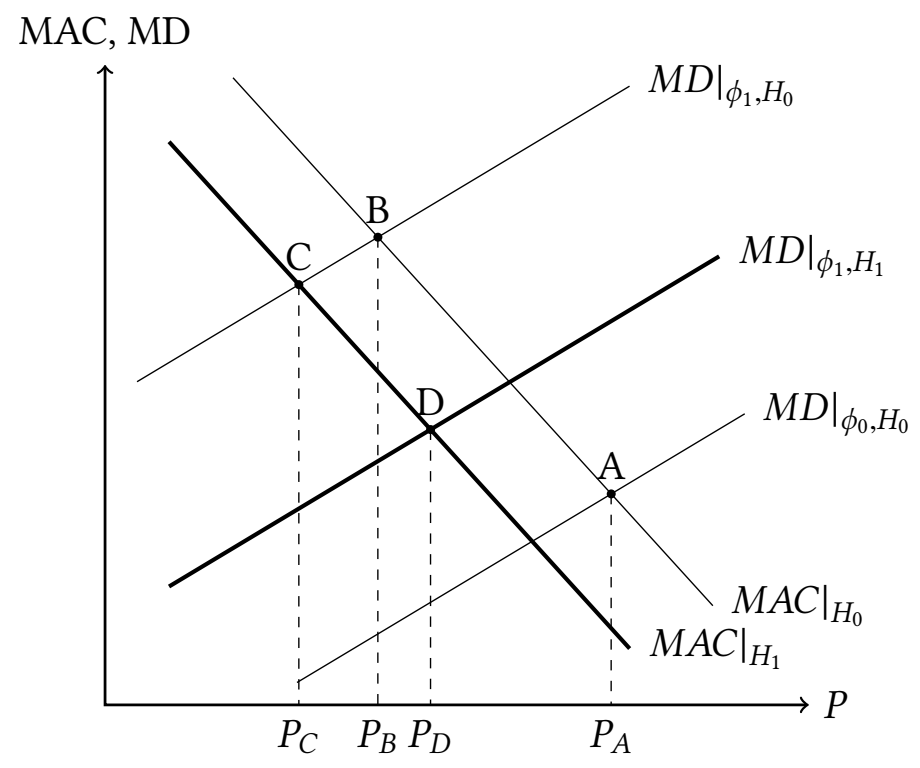

Figure 2: The second-best level of environmental quality when green technology is crowded in.

that in the presence of ITC a larger reduction in pollution obtains as the new equilibrium would be at point $C$. This conclusion, which is in line with the conventional view that induced technical change lowers the cost of environmental policy, is however incomplete and, as we will see shortly, potentially misleading. As a matter of fact ITC exerts a complex influence also on the social marginal damages from pollution and therefore affects the position of the $M D$ curve.

The social value of pollution damages changes both because of the changes in the optimal level of the Pigouvian tax, and because of the changes in the second-best distortion. As refers to the first aspect we can show the following result:

Lemma 4. Following a marginal reduction in pollution, induced technical change increases the optimal Pigouvian tax, whenever

$$
\widetilde{\tau}_{H}^{*} \zeta \widetilde{r}_{P}=\left\{\left[\left(\sigma^{*}-\sigma\right)+\left(\theta^{*}-\theta\right) \widetilde{k}_{H}\right] \omega_{C}+y_{N H}+y_{N K} \widetilde{k}_{H}\right\} \widetilde{\zeta}_{P}<0
$$

This happens under crowding in when

$$
\text { either } \omega_{C}\left(\theta^{*}-\theta\right)+y_{N K}>0 \text {, or } \omega_{C}\left(\theta^{*}-\theta\right)+y_{N K}<0 \cap \widetilde{k}_{H}<-\frac{\omega_{C}\left(\sigma^{*}-\sigma\right)+y_{N H}}{\omega_{C}\left(\theta^{*}-\theta\right)+y_{N K}} \text {; }
$$

and under crowding out when

$$
\omega_{C}\left(\theta^{*}-\theta\right)+y_{N K}<0 \cap \widetilde{k}_{H}>-\frac{\omega_{C}\left(\sigma^{*}-\sigma\right)+y_{N H}}{\omega_{C}\left(\theta^{*}-\theta\right)+y_{N K}} .
$$

Proof. In Appendix A 
The expression in the curly brackets provides insights as to why the Pigouvian tax changes with $H$. On the one hand, changes in investment affect consumption and modify the consumers' willingness to pay for environmental quality. On the other hand, since $\left(y_{N H}+\right.$ $\left.y_{N K} \widetilde{k}_{H}\right)>0$, more $H$ and $K$ make the economy larger, and a larger economy is one worth protecting more against pollution - there is simply more to lose due to environmental degradation.

The Lemma tells us that when technology and physical capital are complements, any change in the economic environment that crowds in investment in technology raises the marginal damages from pollution and hence boosts the demand for environmental quality provided that the externality arising from the over-investment in physical capital is not too strong. At the same time, when investment is crowded out, the demand for environmental quality tends to fall in response to environmental policy unless a sufficiently forceful countervailing reduction in the externality associated with the accumulation of physical capital reverses this outcome.

The second aspect, i.e. the impact of ITC on the second-best correction in (30), is the subject of our next result:

Lemma 5. Following a marginal reduction in pollution, induced technical change increases the stringency of second best taxation whenever, either

$$
\widetilde{r}_{P}>0, \text { or } \widetilde{r}_{P}<-\frac{\widetilde{\theta}_{P}^{*} \widetilde{k}_{H}+\widetilde{\theta}_{H}^{*} \widetilde{k}_{P}}{\zeta\left(\widetilde{\sigma}_{H}^{*}+\widetilde{\theta}_{H}^{*} \widetilde{k}_{H}\right)} .
$$

Proof. In Appendix A

Thus, when environmental policy crowds out technology, investment in both types of capital are necessarily reduced. It follows that the optimal subsidy level decreases for both types of investment. For given levels of $\sigma$ and $\theta$, therefore, the distortion associated with physical capital becomes more salient than the one associated with $H$ and the EPA concentrates on correcting it. This leads to an increase in policy stringency or, equivalently for a given $\tau^{*}$, to an increase in the second-best tax gap.

Conversely, when environmental policy crowds in technology, it makes the knowledge externality more relevant by increasing $\sigma^{*}$. This justifies an increase in $\tau^{S B}$, all else equal. Investment in physical capital, however, is itself affected by the tightening in environmental policy. On the one hand, a fall in pollution reduces the accumulation of its complementary factor, $K$, which reduces the necessity to use environmental policy to correct the learningby-doing distortion. On the other hand, technology and physical capital are themselves complements and crowding in technology leads to an increased demand for physical capital. If the inducement of physical capital via ITC proves strong enough, it offsets the former channel and makes more stringent environmental policy attractive. The condition in the proposition captures precisely this trade-off: only if the joint effect of more $H$ and more $K$ is strong enough will the second-best tax increase.

These lemmas clearly show that in the multiple distortions world we model in this paper ITC might well lead to either an increase or a drop in the demand for environmental quality. 


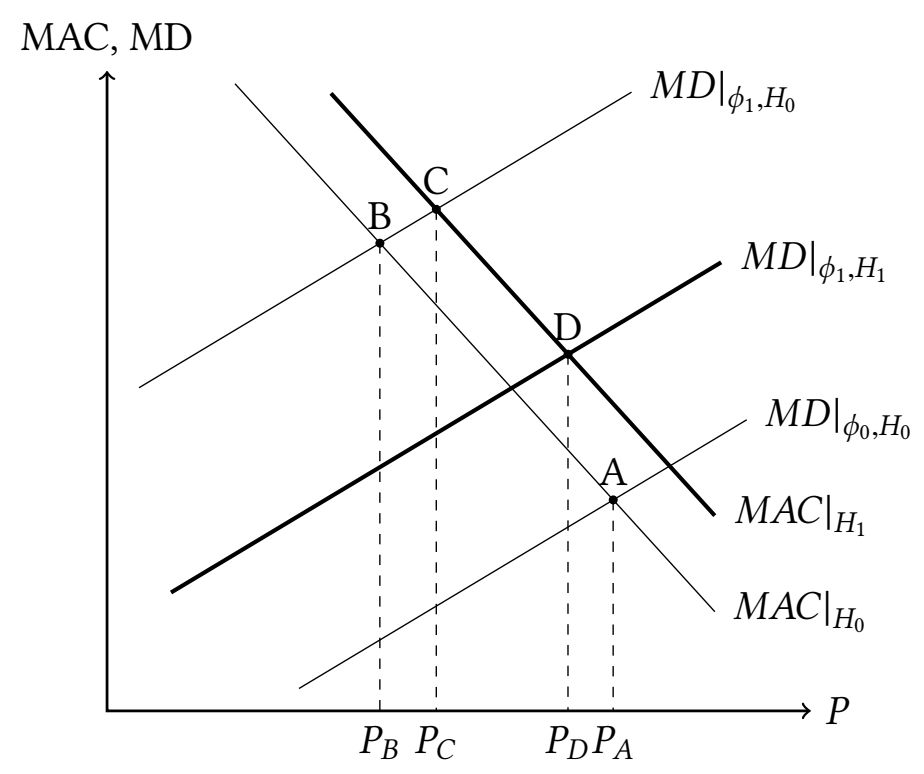

Figure 3: The second-best level of environmental quality when brown technology is crowded in.

An increase in demand would compound the effects of pollution-saving technical change, strengthening the optimistic conclusions held by proponents of the conventional view. Under such circumstances, a further upwards shift of the $M D$ schedule in the figure would lead to an even larger drop in pollution. Perhaps surprisingly, however, even in this pollutionsaving technical change context, things may also go differently. Indeed, if the crowding in of physical capital associated with the increased investment in technology is sufficiently strong, and/or the initial distortion due to the physical capital subsidies large enough, then the opportunity cost of large pollution reductions increases, reducing the demand for environmental quality: this mechanism is captured by a downward shift of the $M D$ curve. If this reduction in the demand for environmental quality is sufficiently pronounced, the final second-best equilibrium may well feature a higher level of pollution under ITC, than would have been the case in the absence of adjustments in investment levels. The necessary condition for such an outcome is given in the text of Proposition 3 and, quite intuitively, requires a large negative impact from the crowding in of physical capital.

An outcome such as the one we just described, in which ITC proves to be a drag for pollution reduction is perhaps less surprising in the context of pollution-using technical change. As shown in Figure 3 while the downward shift of the $M D$ curve is the same as in the previous case, the pollution-using nature of technical change leads to an increase in the marginal cost of pollution abatement. As a consequence of both shifts, the decrease in pollution implied by the greening of preferences is severely curtailed. Notice, moreover, that in the case just discussed ITC might impact negatively on the amount of pollution abated even if the demand for environmental quality were to increase. Indeed, a sufficiently large shift upwards of the $M A C$ curve could still lead to an equilibrium characterized by a level of pollution in excess of $P_{B}$.

To conclude, we need to address the last case covered by Proposition 3, namely the case in 
which the crowding out of technology prevails. From Lemma 3 we know that in this case we will only ever have pollution-saving technical change, and the MAC curve necessarily shift down. Proposition 3 shows that in this case ITC limits pollution reductions only in the case in which the induced crowding out of physical capital is of limited import. Indeed, while lemma 5 tells us that under crowding out the second-best distortion is always increasing, lemma 4 points out that an increase in the marginal damage is possible, provided that technology and physical capital are weak substitutes.

\section{Discussion and conclusions}

Among economists and policy makers an almost universal belief prevails, that ITC makes environmental policy cheaper and more ambitious abatement targets achievable. In successive reports, for example, the Intergovernmental Panel of Climate Change (IPCC) epitomizes this crystallized consensus stating that

"long-term stabilization scenarios highlight the importance of technology improvements, advanced technologies, learning-by-doing, and induced technological change, both for achieving the stabilization targets and cost reduction", (IPCC, 2007, Chapter 3, page 172)

and that

"the availability of new technologies is crucial for the ability to realistically implement stringent carbon policies” (IPCC, 2014, Chapter 15, page 1178).

As we argued in the introduction, however, this view is at odds with the historical record showing that technological change may well turn out to be pollution-using. The existing consensus on the role of ITC simply abstracts from this possibility, and thus concludes that ITC necessarily reduces the cost of environmental policy. Our discussion in this paper strives to reconcile the historical record with the theory, and provides several new insights into the relationship between ITC and (the cost of) environmental policy that have important consequences for the design of environmental policy.

Our first result shows that ITC can increase the cost of environmental policy when technological change is pollution-using, which implies that the marginal cost of pollution abatement increases following the introduction of new technology (Proposition 1). While the literature on environmental policy and induced technical change has almost universally drawn attention to pollution-saving technical change, pollution-using technical change is far from a special case. Both Baker et al. (2008) and Heal and Tarui (2010) discuss several cases of technological progress that leads to increases in the marginal costs of abatement, at least for relatively high abatement levels. Their climate-change related examples include several intermediate technologies, ${ }^{32}$ such as increases in the efficiency of coal-and gas-fired

\footnotetext{
$3^{3}$ Baker et al. (2008) define 'intermediate technologies' somewhat endogenously as "technologies that have lower emissions than Business-as-Usual technologies, but will be substituted away from in the case of very high abatement" [ibid.,p.2806].
} 
electricity generators, carbon capture and sequestration (of less than $100 \%$ of emissions), and cost reduction of efficient gas-fired generators. In the transportation sector their list includes better and less expensive hybrid vehicles as well as bio-diesel. Bauman et al.(2008) present empirical evidence showing that fuel switching in response to increasing regulation led to an increase in marginal abatement costs for $\mathrm{SO}_{2}$ in electricity generation in Korea between 1970 and 1998. Interestingly, all of these technological improvements form part of the portfolio of technological options usually discussed in connection to ITC. Our results here contrast sharply with those of other contributions in the literature (e.g. Goulder and Schneider 1999, Goulder and Mathai 2000; Sue Wing, 2006; Gerlagh, 2007), quite simply because such analyses abstract from the possibility of pollution-using technical change: by assuming that technology is always green and that environmental policy necessarily crowds in new technology, they implicitly end up assuming that ITC is pollution-saving. The key point we make in this paper is that it is the combination of the characteristics of specific innovations, the strength of the production externalities, and the degree of technology-capital complementarity that endogenously determine whether or not in general equilibrium investment in a given technology proves green and is stimulated by environmental policy.

Proposition 2 discusses the welfare costs of ITC under exogenous policy, analyzing both the case where a quantity instrument is used, and the case when a price instrument is instead favoured. In this part of the paper we emphasize the complex interactions existing between environmental externalities and investment spillovers. We show, for example, that the welfare benefits from a drop in pollution may be partly offset by the crowding out underprovided technology. Our analysis transparently reveals the crucial role played by incompletely internalized external effects, and sheds additional light on differences across estimates of the value of ITC in CGE models. For example, Buonanno et al. (2003) neglect the role of market failures in $\mathrm{R} \& \mathrm{D}$, and obtain larger estimates for the impact of ITC on the cost of environmental policy than Popp (2004), who explicitly recognizes the divergence between the social and the private returns to innovation.

Our third result focuses on the importance of general equilibrium effects in this debate. Proposition 3 emphasizes that ITC also affects the consumers' marginal willingness to pay for environmental quality improvements. As the willingness to pay changes, so does the relative costliness of environmental policy and the equilibrium level of environmental quality. We show that shifts in both the MAC curve and the marginal damage curve are crucial to the final outcome, and that a negative role for ITC may emerge even when technological change is pollution-saving from the point of view of the representative firm. One key difference exists between our analysis and the existing literature. In our general equilibrium model, changes in investment affect income and consumption and hence, through shifting the demand for environmental quality, affect marginal damages. Most of the existing literature, however, frames this question in a partial equilibrium context, typically assuming that the marginal benefits from pollution reduction equal (the present value of avoided) marginal pollution damages, that only depend on environmental magnitudes (pollution stock, environmental quality, etc.). In the context of our model, this would imply that marginal damages depend on $N$, but not $H$. By construction, then, ITC does not affect environmental policy via changes in marginal damages, and the general equilibrium effects we find here are neglected. Both Goulder and Mathai (2000) and Heal and Tarui (2010), for example, posit a social loss function that is additively separable in abatement costs and dam- 
ages, where the latter only depend on cumulative emissions. The sharp contrast between the unambiguously positive effect of ITC in partial equilibrium models, and our much more nuanced conclusions highlights the importance of considering general equilibrium effects when gauging the relevance of ITC for environmental policy.

Overall our analysis paints a profoundly different picture of the link between ITC and the cost of environmental policy from the one commonly found in the literature. Indeed a far less flattering role may emerge for ITC when technology is complementary with physical capital that needs polluting inputs or when additional uncorrected distortions are present in the economy. Arguably, these situations are far from uncommon, and represent a more realistic description of actual economies than stylized first-best models.

The policy implications of our analysis are significant, especially since our results are obtained in an empirically plausible framework. In a second-best context with multiple externalities, induced innovation, far from being the deus ex-machina that enables the achievement of ambitious environmental targets, was shown to have the potential to increase the cost of environmental regulation. Our discussion in this paper suggests that, as long as traditional polluting sectors are subsidized and the economy remains locked into pollutionintensive technologies, the incremental (green) innovation induced by environmental policies is likely to become counterproductive and to only increase demand for pollution in these sectors.

Our research indicates that a comprehensive approach to environmental problems - i.e. one which takes into account the productive impact of increases in environmental quality, the need to correct technology spillovers, and the type of technologies that are likely to emerge from the purposive activity of innovators - is needed to take full advantage of the potential benefits of ITC, avoid the possible costs it entails, and ensure that environmental policy achieves the desired shade of green.

\section{References}

Acemoglu, D., P. Aghion, L. Bursztyn, And D. Hemous (2012): "The Environment and Directed Technical Change," American Economic Review, 102, 131-166.

Amir, R., M. Germain, And V. Van Steenberghe (2008): "On the Impact of Innovation on the Marginal Abatement Cost Curve," Journal of Public Economic Theory, 10, 985-1010.

Antweiler, W., B. R. Copeland, and M. S. Taylor (2001): "Is Free Trade Good for the Environment?" American Economic Review, 91, 877-908.

Arrow, K. (1962): “The Economic Implications of Learning by Doing," Review of Economic Studies, 29, 155-173.

Baker, E., L. Clarke, And E. Shittu (2008): "Technical Change and the Marginal Cost of Abatement," Energy Economics, 30, 2799-2816.

Bauman, Y., M. LeE, AND K. Seeley (2008): "Does Technological Innovation Really Reduce Marginal Abatement Costs? Some Theory, Algebraic Evidence, and Policy Implications," Environmental and Resource Economics, 40, 507-527. 
Brechet, T. And G. Meunier (2014): "Are Clean Technology and Environmental Quality Conflicting Policy Goals?” Resource and Energy Economics, 38, 61-83.

Buonanno, P., C. Carraro, and M. Galeotti (2003): "Endogenous induced technical change and the costs of Kyoto," Resource and Energy Economics, 25, 11-34.

Coady, D., I. Parry, L. Sears, and B. Shang (2015): "How Large Are Global Energy Subsidies?” IMF Working Paper WP/15/105.

Cole, M. A. ANd R. J. R. Elliott (2003): "Determining the trade-environment composition effect: the role of capital, labor and environmental regulations," fournal of Environmental Economics and Management, 46, 363-383.

Davis, L. W. (2014): “The Economic Cost of Global Fuel Subsidies”, American Economic Review, 104, 581-85.

Edenhofer, O., K. Lessmann, C. Kemfert, M. Grubb, and J. Köhler (2006): "Induced technological change: Exploring its implications for the economics of atmospheric stabilization; Synthesis report from the innovation modelling comparison project," The Energy fournal, Special Issue no.1, 57-108.

Gans, J. (2012): "Innovation and Climate Change Policy," American Economic fournal: Economic Policy, 4, 125-145.

Gerlagh, R. (2007): "Measuring the Value of Induced Technological Change," Energy Policy, $35,5287-5297$.

Goulder, L. H. (2004): “Induced Technological Change and Climate Policy," Tech. rep., Pew Center on Global Climate Change.

Goulder, L. H. And K. Mathai (2000): "Optimal $\mathrm{CO}_{2}$ Abatement in the Presence of Induced Technological Change," Journal of Environmental Economics and Management, 39, 1-38.

Goulder, L. H. AND S. Schneider (1999): "Induced Technological Change and the attractiveness of $\mathrm{CO}_{2}$ Abatement Policies," Resource and Energy Economics, 21, 211-253.

Griliches, Z. (1992): “The search for R\&D spillovers," Scandinavian fournal of Economics, 94, S29-47.

Heal, G. AND N. TARUi (2010): "Investment and emission control under technology and pollution externalities," Resource and Energy Economics, 32, 1-14.

InTRILIGATOR, M. D. (1965): "Embodied technical change and productivity in the United States, 1929-1958," Review of Economics and Statistics, 47, 65-70.

IPCC (2007): Climate Change 2007: Mitigation. Contribution of Working Group III to the Fourth Assessment Report of the Intergovernmental Panel on Climate Change, Metz, B., O.R. Davidson, P.R. Bosch, R. Dave and L.A. Meyer (eds.), Cambridge, UK: Cambridge University Press. 
--- (2014): Climate Change 2014: Mitigation of Climate Change. Contribution of Working Group III to the Fifth Assessment Report of the Intergovernmental Panel on Climate Change, O. Edenhofer, R. Pichs-Madruga, Y. Sokona, E. Farahani, S. Kadner, K. Seyboth, A. Adler, I. Baum, S. Brunner, P. Eickemeier, B. Kriemann, J. Savolainen, S. Schlömer, C. von Stechow, T. Zwickel, and J.C. Minx (eds.), Cambridge, UK: Cambridge University Press.

Jaffe, A. B., R. G. Newell, And R. N. Stavins (2003): "Technological Change and the Environment," in Handbook of Environmental Economics, ed. by K. Mäler and J. R. Vincent, Amsterdam: Elsevier Science, vol. 1, 461-516.

JonEs, C. I. (1995): “R\&D-Based Models of Economic Growth,” fournal of Political Economy, 103, pp. 759-784.

Milliman, S. R. And R. Prince (1989): "Firms Incentives to Promote Technological Change in Pollution Control," Journal of Environmental Economics and Management, 17, 247-265.

Nordhaus, W. D. (2002): "Modeling induced innovation in climate-change policy," in Technological Change and the Environment, ed. by A. Grubler, N. Nakicenovic, and W. D. Nordhaus, Wahsington, DC: Resources for the Future Press, 182-209.

Parry, I., W. A. Pizer, And C. Fischer (2003): "How Large are the Welfare Gains from Technological Innovation Induced by Environmental Policies?” fournal of Regulatory Economics, 23, 237-255.

Perino, G. And T. Requate (2012): "Does more stringent environmental regulation induce or reduce technology adoption?: When the rate of technology adoption is inverted Ushaped," Journal of Environmental Economics and Management, 64, 456-467.

Popp, D. (2004): "ENTICE: Endogenous Technical Change in the DICE Model of Global Warming," Journal of Environmental Economics and Management, 48, 742-768.

Requate, T. And W. Unold (2003): "Environmental Policy Incentives to Adopt Advanced Abatement Technology: Will the True Ranking Please Stand Up?” European Economic Review, 47, 125-146.

Romer, P. M. (1986): “Increasing Returns and Long Run Growth,” fournal of Political Economy, 94, 1002-37.

Solow, R. (1960): "Investment and technical progress," in The Theory and Empirical Analysis of Production, ed. by M. Brown, Dordrecht: Columbia University Press, 25-50.

Stern, N. (2006): "Stern Review on The Economics of Climate Change," Tech. rep., HM Treasury, London.

Sue Wing, I. (2006): "Induced Technological Change: Firm Innovatory Responses to Environmental Regulation," mimeo, Boston University. 


\section{A Proofs of results omitted in the main text}

\section{Proposition 2}

$\operatorname{Ad}[$ That ITC reduces the welfare gains from a marginal tightening of the emissions cap requires $\left.\frac{\mathrm{d} U}{\mathrm{~d} \tau}\right|_{\widetilde{r}_{P}=0}>\left.\frac{\mathrm{d} U}{\mathrm{~d} \tau}\right|_{\widetilde{r}_{P} \neq 0}$. From (27), this implies

$$
\left[\left(\sigma^{*}-\sigma\right)+\left(\theta^{*}-\theta\right) \widetilde{k}_{H}\right] \widetilde{\zeta r_{P}}>0 \text {. }
$$

The statement in the proposition follows immediately taking into account that $\zeta>0$.

Ad ii From equation (28, we have in this case that:

$$
\begin{aligned}
\left.\frac{\mathrm{d} U}{\mathrm{~d} \tau}\right|_{\widetilde{r}_{P}=0}>\left.\frac{\mathrm{d} U}{\mathrm{~d} \tau}\right|_{\widetilde{r}_{P} \neq 0} \Leftrightarrow \\
\Leftrightarrow \frac{\left(\tau^{*}-\tau\right)-\left(\theta^{*}-\theta\right) \widetilde{k}_{P}}{\widetilde{m}_{P}}<\frac{\left[\left(\tau^{*}-\tau\right)-\left(\theta^{*}-\theta\right) \widetilde{k}_{P}\right]-\left[\left(\sigma^{*}-\sigma\right)+\left(\theta^{*}-\theta\right) \widetilde{k}_{H}\right] \zeta \tilde{r}_{P}}{\widetilde{m}_{P}+\widetilde{m}_{H} \zeta \tilde{r}_{P}} .
\end{aligned}
$$

Recalling that $\widetilde{m}_{P}+\widetilde{m}_{H} \tilde{r}_{P}<0$, we can rewrite the last expression as:

$$
1+\frac{\widetilde{m}_{H}}{\widetilde{m}_{P}} \widetilde{r}_{P}>1-\frac{\left(\sigma^{*}-\sigma\right)+\left(\theta^{*}-\theta\right) \widetilde{k}_{H}}{\left(\tau^{*}-\tau\right)-\left(\theta^{*}-\theta\right) \widetilde{k}_{P}} \widetilde{r}_{P} .
$$

Simple manipulations, and the fact that $\widetilde{m}_{P}<0$, lead to the inequalities in the statement of the Proposition.

\section{Proposition 3}

From (32), it is clear that, since $\left(\widetilde{m}_{P}-\widetilde{\tau}_{P}^{*}+\widetilde{\theta}_{P}^{*} \widetilde{k}_{P}\right)<0$, the change in pollution driven by a greening of preferences is smaller under ITC whenever the term identified by the brace is negative. First, notice that from (25) and (30), and the fact that 21) implies that $\widetilde{k}_{H}=$ $\frac{y_{H K}}{j_{K K}-y_{K K}}$, it is possible to write:

$$
\left(\widetilde{m}_{H}-\widetilde{\tau}_{H}^{*}\right)=\widetilde{r}_{P}-\omega_{C}\left[\left(\sigma^{*}-\sigma\right)+\left(\theta^{*}-\theta\right) \widetilde{k}_{H}\right] .
$$

It follows that the ITC term in (32) can be expressed as:

$$
\widetilde{r}_{P}\left\{\left(1+\zeta \widetilde{\sigma}_{H}^{*}+\zeta \widetilde{\theta}_{H}^{*} \widetilde{k}_{H}\right)-\omega_{C}\left[\left(\sigma^{*}-\sigma\right)+\left(\theta^{*}-\theta\right) \widetilde{k}_{H}\right]+\widetilde{\theta}_{P}^{*} \widetilde{k}_{H}+\widetilde{\theta}_{H}^{*} \widetilde{k}_{P}\right\} .
$$

Solving for the ITC term to be negative, recalling Assumptions 4 and 6 , immediately gives the restrictions in the statement above.

\section{Lemma 4}

ITC increases the demand for environmental quality whenever the change in $H$ induced by the reduction in pollution causes $\tau^{*}$ to increase. Formally, this requires: $\widetilde{\tau}_{H}^{*}(\mathrm{~d} H / \mathrm{d} P) \mathrm{d} P>0$, 
$\forall \mathrm{d} P<0$, or equivalently: $\widetilde{\tau}_{H}^{*}(\mathrm{~d} H / \mathrm{d} P)<0$. Recall that $\tau^{*}$ can be written as

$$
\widetilde{\tau}^{*}(H, P) \equiv y_{N}(H, \widetilde{k}, P,-P)+\omega(\widetilde{c},-P ; \phi) .
$$

Upon partial differentiation with respect to $H$, we find:

$$
\widetilde{\tau}_{H}^{*}=y_{N H}+y_{N K} \widetilde{k}_{H}+\omega_{C} \widetilde{c}_{H} .
$$

From (29), using (15), 16) and the definitions in (19) and (20), we get:

$$
\widetilde{c}_{H}=y_{H}-i_{H}-i_{\bar{H}}+\left(y_{K}-j_{K}-j_{\bar{K}}\right) \widetilde{k}_{H}=\left(\sigma^{*}-\sigma\right)+\left(\theta^{*}-\theta\right) \widetilde{k}_{H} .
$$

Using this expression and the definition of $\mathrm{d} H / \mathrm{d} P$ from 26 in A.1), we immediately get:

$$
\widetilde{\tau}_{H}^{*} \widetilde{r}_{P}=\left\{\left[\left(\sigma^{*}-\sigma\right)+\left(\theta^{*}-\theta\right) \widetilde{k}_{H}\right] \omega_{C}+y_{N H}+y_{N K} \widetilde{k}_{H}\right\} \widetilde{\zeta_{P}}<0 .
$$

Given the positiveness of $\zeta$, it is a simple matter of algebra to solve for the inequalities in the text of the Lemma.

\section{Lemma 5}

First of all, notice that for given $\tau^{*}$ the statement in the Lemma is equivalent to requiring that

$$
\frac{\mathrm{d}\left(\tau^{S B}-\tau^{*}\right)}{\mathrm{d} P}<0
$$

Totally differentiating (30) abstracting from higher-order effects by suppressing all thirdorder partial derivatives, ${ }^{33}$ yields:

$$
\mathrm{d}\left(\tau^{S B}-\tau^{*}\right)=-\left[\widetilde{\theta}_{P}^{*} \widetilde{k}_{P}+\widetilde{\theta}_{P}^{*} \widetilde{k}_{H} \widetilde{\zeta} \widetilde{r}_{P}\right] \mathrm{d} P-\left[\widetilde{\theta}_{H}^{*} \widetilde{k}_{P}+\widetilde{\sigma}_{H}^{*} \widetilde{\zeta r_{P}}+\widetilde{\theta}_{H}^{*} \widetilde{k}_{H} \widetilde{\zeta r_{P}}\right] \mathrm{d} H .
$$

Since $\mathrm{d} H=\frac{\mathrm{d} H}{\mathrm{~d} P} \mathrm{~d} P$, using (26), we immediately get:

$$
\frac{\mathrm{d}\left(\tau^{S B}-\tau^{*}\right)}{\mathrm{d} P}=-\widetilde{\theta}_{P}^{*} \widetilde{k}_{P}-\underbrace{\left[\widetilde{\theta}_{P}^{*} \widetilde{k}_{H}+\widetilde{\theta}_{H}^{*} \widetilde{k}_{P}+\widetilde{\sigma}_{H}^{*} \widetilde{\zeta}_{P}+\widetilde{\theta}_{H}^{*} \widetilde{k}_{H} \widetilde{r}_{P}\right] \widetilde{r}_{P}}_{\text {ITC }} .
$$

It follows that for ITC to increase the difference $\left(\tau^{S B}-\tau^{*}\right)$ as $P$ is reduced, the term indicated with ITC in the expression above must be positive. Using (18) and (19), together with (8) and (21) to express $\sigma^{*}$ and $\theta^{*}$ as functions of $H$ and $P$ only, it immediately follows that $\widetilde{\sigma}_{H}^{*}=-\left(i_{\bar{H} H}+i_{\bar{H} \bar{H}}\right), \widetilde{\theta}_{P}^{*}=-\left(j_{\bar{K} K}+j_{\bar{K} \bar{K}}\right) \widetilde{k}_{P}$, and $\widetilde{\theta}_{H}^{*}=-\left(j_{\bar{K} K}+j_{\bar{K} \bar{K}}\right) \widetilde{k}_{H}$. From the definition of $\widetilde{k}_{P}$ and $\widetilde{k}_{H}$, and Assumptions 2 and 4 it is clear that all these derivatives are positive, and that the ITC term is necessarily positive as long as $\widetilde{r}_{P}$ is also positive. When $\widetilde{r}_{P}<0$, instead, it is a simple matter of algebraic manipulations to show that the ITC term is positive whenever,

$$
\widetilde{r}_{P}<-\frac{\widetilde{\theta}_{P}^{*} \widetilde{k}_{H}+\widetilde{\theta}_{H}^{*} \widetilde{k}_{P}}{\zeta\left(\widetilde{\sigma}_{H}^{*}+\widetilde{\theta}_{H}^{*} \widetilde{k}_{H}\right)}
$$

\footnotetext{
${ }^{33}$ Notice that this implies from (26), 25 and the definition of $\widetilde{k}_{P}$ in $(27)$, that we treat $\widetilde{r}_{P}, \widetilde{k}_{H}$ and $\widetilde{k}_{P}$ as constants.
} 